\title{
In-Silico Mutajenisite Tahmininde İstatistiksel Öğrenme Modeli
}

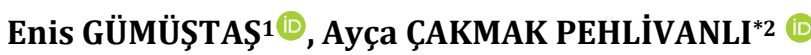

1,2Mimar Sinan Güzel Sanatlar Üniversitesi, Fen Edebiyat Fakültesi, İstatistik Bölümü, 34380, İstanbul, Türkiye

(Alınış / Received: 23.01.2021, Kabul / Accepted: 02.03.2021, Online Yayınlanma / Published Online: 15.08.2021)

\author{
Anahtar Kelimeler \\ Sinıflama, \\ Topluluk Öğrenmesi, \\ XGBoost, \\ LightGBM, \\ Değişken Seçimi, \\ Toksisite
}

\begin{abstract}
Özet: Toksisite testleri arasında, bir etken nedeniyle ortaya çıabilecek genetik değişim (mutasyon) olarak tanımlanabilen mutajenisite önemli yer tutmaktadır. Bu çalışmada genel olarak mutajenisite belirleme sürecini iyileştirebilmek adına insilico yaklaşım kapsamında istatistiksel öğrenme algoritmaları kullanılmıștır. Söz konusu yaklaşım deneyler ile elde edilen mutajenisite bilgisi içeren molekül setine uygulanmış ve dikkate değer sınıflama başarıları elde edilmiștir. Çalıșmada kullanılmak üzere literatürde bulunan, moleküllerden oluşan Bursi ile Benchmark veri setleri birleştirilmiş ve Molecular Operating Environment (MOE) programı aracılığı ile moleküllerin özellikleri hesaplanmıştır. Hesaplama sonucunda 10835 gözleme ve 193 değișkene sahip veri seti üzerinde karar ağaçları algoritmaları uygulanarak grid arama yaklaşımı ile parametre seçimi gerçekleştirilmiştir. Elde edilen en iyi parametreler ile kurulan modeller sonucunda değişkenlerin seçimi mutajenisiteyi tahmin etmedeki önem düzeylerine göre yapılmış ve verinin boyutu en etkili 72 değişkene indirgenmiştir. Seçilen değişkenlerden oluşan yeni veriye farklı istatistiksel öğrenme algoritmaları uygulanmıș ve içlerinden en iyi sonuç veren beş sınıflama algoritmasına karar verilmiştir. Parametre en iyilemesi ile model başarımları arttırılan bu algoritmalar kullanılarak yaklaşı \%90 mutajenisiteyi doğru sınıflama oranları elde edilmiștir.
\end{abstract}

\section{Statistical Learning Model for In-Silico Mutagenicity Prediction}

\section{Keywords}

Classification,

Ensemble Learning,

XGBoost,

LightGBM,

Feature Selection,

Toxicity

\begin{abstract}
Among the toxicity tests, mutagenicity defined as a genetic change that can occur due to an agent, has an important place. In this study, statistical learning algorithms were used within the scope of in-silico approach in order to improve the mutagenicity determination process in general. This approach has been applied to the set of molecules containing mutagenicity information obtained by experiments and remarkable classification success were achieved. In order to use in this study, Bursi and Benchmark data sets consisting of molecules found in the literature were combined and the properties of molecules were calculated by means of the Molecular Operating Environment (MOE). As a result of the calculation, decision trees algorithms were applied on the data set with 10835 molecules and 193 variables and parameter selection was performed with grid search approach. The selection of variables was made according to their level of importance in predicting mutagenicity as a result of models established with the best parameters obtained, and the number of descriptors variables was reduced to the 72 most effective descriptor variables. Various statistical learning algorithms were applied to the reduced data set consisting of the selected variables, and five classification algorithms with the best results were decided. By the algorithms whose model performances were increased by means of parameter optimization, accurate prediction rates were obtained approximately $90 \%$ for mutagenicity classification.
\end{abstract}

\section{Giriş}

Gelişen teknolojilerle birlikte canlı organizmanın dışında yapılan in-vitro ve canlı organizma üzerinde yapılan in-vivo deneyler yerini laboratuvar deneylerine gereksinim duymadan bilgisayar ortamında geliștirilen istatistiksel ve hesaplamalı yöntemlere bırakmaya başlamıştır. Genel olarak insilico adı verilen bu yöntemler in-vivo ve/ya in-vitro testlere geçmeden önce aday ilaç moleküllerine yönelik öngörme, önbilgi verebilme yetkinliğindedir. 
Doğru bir in silico yaklaşım, moleküle ait elde edilen bilginin laboratuvar deneylerine geçilip geçilmemesi konusunda yönlendirici olmasının yanında yapılacak testlerin tasarımında daha az deney hayvanı kullanılması, kullanılacak konsantrasyonun önceden belirlenebilmesi, zaman ve maliyetin azaltılabilmesi gibi avantajlar da sağlayabilir.

Günümüzde kimyasalların yasal düzenlemelerinde (ilaç molekülleri, gıda katkı maddeleri, kozmetik gibi) çeşitli toksisite testlerinden yararlanılır. Özellikle aday ilaç moleküllerinin klinik çalışmalarına devam edebilmesi için bir etken nedeniyle ortaya çıabilecek genetik değişime (mutasyon) karşılık gelen mutajenik etkilerinin olmaması önkoşuldur. Toksisiteye yol açması nedeniyle mutajenisitenin önceden tespiti çok önemlidir. Bu tespitin yapılabilmesi için de çeşitli yöntemlerin yanı sıra istatistiksel öğrenme yaklaşımları çoklukla kullanılmaktadır.

In silico çalışmalar genel olarak kurala ve uzman bilgisine dayalı sistemler ve kantitatif yapı-aktivite ilişkisi (QSAR) olarak da bilinen istatistiksel yöntemlere dayalı yaklaşımlar olmak üzere iki grupta toplanabilir [1-3]. Özellikle 90'ların sonunda hız kazanan kurala ve uzman bilgisine dayalı sistemlere ilişkin erken dönem çalışmalarında kimyasal yapılar ile gözlemlenen toksik çıtılar arasındaki ilişkiler incelenmiş, çeşitli yazılımlar karşılaştırmalı olarak ortaya konmuştur [4]. Bu çalışmalara aleternatif olarak istatistiksel yöntemlere dayalı modellemeler ve yazılımlar özellikle moleküllerin fizikokimyasal özelliklerine dayalı olarak biyolojik aktivitelerini çeşitli makine öğrenmesi algoritmaları ile tahmin etmekte kullanılmıştır [5]. Mazzatorta ve ark. mutajenisite tahmini için bu iki yaklaşımı birleștiren hibrit bir in silico yaklaşım önermiş ve test verisi üzerinde \%85 tahmin başarısı elde etmişlerdir [6]. 2000'li yılların başlarında bu alanda yapılan çalışmalarda in silico yöntem olarak özellikle destek vektör motroları yaygın olarak tercih edilmiştir. Zheng ve ark. kimyasal moleküllerin mutajenik olasılıklarının tahmininde \%85 başarı elde ederken, Liao ve ark. yinelemeli bölünme ile seçtikleri değişkenlerden oluşan üç farklı veri setinden destek vektör motorları kullanarak \%81.4, \%87 ve \%87.3 oranında sınıflama başarısına ulaşmışlardır [7-8].

2012 yılında $\mathrm{Xu}$ ve ark. tarafindan mutajenisiste tahmininde \%56'sı mutajen olan 7617 farklı bileşik içeren bir çalışma yapılmıştır. Çalışmada yaygın kullanılan beş farklı öğrenme yöntemi ile model oluşturmuş, oluşan modellerin performansı 831 farklı bileşik içeren harici veri seti ile sınanmış ve \%90.4 ile \%98 arası başarı elde edilmiştir [9] Son yıllarda bu alanda çeşitli çalışmalar yapılmıştır. Moorthy ve ark. veri madenciliği algoritmaları ile elde ettikleri modelleri sıra fark toplamı ile sıralamış ve rastgele orman algoritması ile \%70 başarı elde etmiştir. 2017 yılında yapılan bu araştırmada 1481 molekülden oluşan veri setinin mutajenik ve kanserojen bilgileri kullanmıştır [10]. Yine aynı yıl Zhang ve arkadaşları yeni bir Naive Bayes yaklaşımı önermiş ve ilaç moleküllerinin tahmininde ekili olan mutajenisite bilgisi içeren veri seti üzerine uygulamıștır. Kullandığı farklı sinama veri setleri üzerinde $\% 70.3$ ve \%90.9 düzeyinde başarı elde etmişlerdir [11]. Webb ve arkadaşları destek vektör makineleri ile rastgele orman algoritmalarını kullanarak mutajenisite verisi üzerinde 2014'te yaptıkları çalışmada \%82 başarı elde etmişlerdir [12]. Seal ve arkadaşları tarafından üç farklı mutajenisite veri seti üzerine çeşitli sınıflama algoritmaları uygulanmış ve \%79 ile \% 85 arasında başarı elde edilmiştir [13].

Son yıllarda uygulamalı matematik, istatistik ve bilgisayar alanlarında yaşanan gelişmeler, kimya, biyoloji ve genetikte kullanılan karmaşık sistemlerin çözümü için yeni disiplinlerin doğuşuna neden olmuştur. $\mathrm{Bu}$ disiplinler sayesinde kimyasal ve biyolojik verilerden gerçek bilginin elde edilebilmesi veya saklı bilgilerin açığa çıkarılması sağlanabilmektedir. Bu kapsamda Ji ve arkadaşları tarafindan 2019 yılında kombine ilaç tedavilerinin iyileştirme etkisini artırmak ve beraberinde gelen yan etkileri azaltmak amacı ile yapılan çalışmada ilaçlar sinerjist ve antagonist etkiler bakımından sınıflandırılmıştır. Çalışmada XGBoost algoritması, ilaçların beş özelliği temel alınarak uygulanmış ve insilico yaklaşımın deneysel yaklaşımlara göre çok daha etkili olduğu gösterilmiștir [14].

Biyolojik moleküllerden elde edilen verilerin boyutu çok büyük olabilmektedir. Büyük boyutlu veriler ise daha yüksek hesaplama gücüne ve buna bağlı olarak artan hesaplama sürelerine ihtiyaç duymaktadır. Bunun yanı sıra gereksiz ve ilişkisiz değişkenlerin çıkarılmasıyla birlikte modeli açıklayan değişkenler elde edilmektedir. Bu yöntem ile hem kaynak ihtiyacı gereksinimi azalırken hem de daha az değişken kullanılarak bilgi kaybı yaşanmadan daha hızlı ve anlaşılır biçimde kurulan modelin başarımı bilgi kaybı yaşanmadan artmaktadır. Bu amaçla çalışmada ilk olarak veri boyutunun düşürülmesi için değişken seçimi yapılmıştır ve daha sonra kullanılacak yöntemler için gerekli parametre seçimleri yapılarak elde edilen daha düşük boyutlu verilere mutajenisite belirleme sürecini iyileştirebilmek adına çeşitli sınıflama yöntemleri uygulanmıştır. Söz konusu yaklaşım, kullanılarak deneyler ile elde edilen mutajenisite bilgisi içeren molekül setine uygulanmış ve sınıflama başarılarında dikkate değer düzeyde artış sınıflama başarıları görülmüştür.

\section{Materyal ve Metot}

Bir ilacın mükemmel ADME-Tox (Emilim, Dağılım, Metabolizma, Eliminasyon, Toksisite) özelliklerine sahip olarak piyasaya girmiş olması hayati önem tașımaktadır. Toksisitenin ilaç geliștirmenin tüm aşamalarında başlıca başarısızlık nedeni olmasından dolayı, ilaç toksikolojisi klinik öncesi çalışmalardaki 
en önemli araştırma alanlarından biri olmuştur. Bu nedenle, daha önce de belirtildiği gibi ilaç keşif sürecinde kilit rol oynayan molekül toksisitesini insilico tahmin yöntemleri ile önceden belirlemek uzun ve çok masraflı olan ilaç keşif sürecinde zaman ve maliyet bakımından önemli bir tasarruf sağlamaktadır.

Çalışma kapsamında, literatürde bulunan ve moleküllerden oluşan Bursi ve Benchmark veri setleri kullanılmıştır $[15,16]$. Bu veri setleri kullanılarak yapılan çalışmalardan farklı olarak 4337 molekülden oluşan Bursi mutajenisite veri seti ile 6512 molekülden oluşan Benchmark veri seti birleştirilmiş ve tekrarlı gözlemler çıkartılmıştır. 10833 moleküle sahip birleştirilmiş veri seti molekül bilgisine ek olarak her bir moleküle ait aktif olup olmama (aktivite) bilgisini de içermektedir. Moleküllere ilișkin kimyasal tanımlayıcıların (molecular descriptors) hesaplanmasında ise kimyasal hesaplama ve moleküler modelleme aracı olan Molecular Operating Environment (MOE) programı kullanılmıştır [17]. MOE aracılığı ile 2 boyutlu kantitatif yapı-aktivite ilişki (2D QSAR) değişkenleri hesaplanmıştır. Bu değişkenler genel olarak; alt bölümlere ayrılmış yüzey alanı (subdivided surface area), bitişiklik ve uzakllık matrisi (adjacency and distance matrix), farmakofor özellikleri (pharmacophore features), kısmi yükler (partial charges), KierHall bağlantısı ve Kappa şekil endeksleri (Kier\&Hall connectivity and Kappa shape indices), atom ve bağ sayıları (atom and bond counts), Hueckel teorisi tanımlayıcıları ve fiziki özellikler (physical properties) olmak üzere çeşitli gruplardan gelmektedir [17]. Sonuç olarak elde edilen veri seti, tahmin edilmek istenen mutajenisite bilgisine sahip olan aktivite değişkeni ile birlikte toplamda 193 değişkenden oluşan büyük bir veri seti haline dönüşmüştür. Veri seti, rastgele bir biçimde \%70'i eğitim ve \%30'u da sınama seti olacak şekilde ayrlarak aktivite bilgisine göre mutajen ve nonmutajen olarak etiketlendiğinde dağılım Tablo 1'de verildiği gibi özetlenmiştir.

Tablo 1. Veri setinin sınıflara göre eğitim ve sinama setindeki dağılımı.

\begin{tabular}{lccc}
\hline & Mutajen & Non-mutajen & Toplam \\
\hline Eğitim & 4110 & 3473 & 7583 \\
Sinama & 1792 & 148 & 3250 \\
Toplam & 5902 & 4931 & 10833 \\
\hline
\end{tabular}

\subsection{Sinıflama Algoritmaları}

Sınıflama yöntemlerinin ifadelerinde kolaylık açısından yöntemlerin literatürde yaygın kullanılan isim ve kısaltmaları tercih edilmiştir. Buna göre, çalışmada geçen rasgele orman (random forest) RF, aşırı rasgeleleştirilmiş ağaçlar (extremly randomized trees) ExtraTrees, aşırı gradyan arttırma (extreme gradient boosting) XGBoost, hafif gradyan arttırma LightGBM, torbalama (bagging) olarak kullanılmıştır. Çalışmada sınıflama için ağaç tabanlı yöntemler tercih edilmiştir. Karar ağaçları sınıf bilgisi bulunan veriden tümevarım yöntemi ile çıkarım yaparak öğrenen ve ağaç şekline benzer yapısı olan denetimli bir öğrenme algoritmasıdır. Tahmin edilmek istenen hedef değişkenin ölçüm türüne göre regresyon ve sınıflama problemleri için kullanılabilir.

Rastgele orman (RF), 2001 yılında Leo Breiman tarafından önerilmiş bir karar ağacı algoritmasıdır. Bootstrap örnekleme kullanarak veri içerisinden yeni alt veri setleri oluşturur ve bu her alt veri seti için bir ağaç oluşturulur. Oluşturulan bu ağaçlarda yeni düğüm belirlenirken seçili kritere (gini, entropi) göre en iyi bölünme için seçim yapılarak ve yeni dal açllır. Bu seçim sırasında en çok kazancı sağlayan değişken hesaplandığı için eğitim süresi uzun sürmektedir. Bootstrap kullandığı için varyansı düşük ve aşırı öğrenmeye meyilli olmayan modeller oluşturur [18].

2006 yılında Geurts ve arkadaşları tarafından önerilen ExtraTrees algoritması RF algoritmasına benzer olup ağaç yapısını daha rassal hale getirir. RF algoritmasında dügüm seçimi sırasında uygun bölünme noktası için belirlenen kritere göre kazanç hesaplanırken, ExtraTrees için bu seçim rastgele yapılır. Böylece ağaç yapısındaki çeşitlilik artar ve bu şekilde değişkenliğin düşürülmesi amaçlanır. Rastgele seçim yapması sebebiyle de ara bir hesaplama süreci olan bilgi kazancı veya gini indeksi hesabı olmadığı için RF algoritmasına göre göre daha hızlı çalışan bir algoritmadır [19].

Bagging sinıflayıcısında ise bootstrap örnekleme yöntemi ile veri seti içerisinden rastgele iadeli örneklemler çekilir ve bu șekilde alt veri setleri oluşturulur. Oluşturulan bu alt veri setlerine tekli karar ağaçları uygulanır. Elde edilen sonuçlar içerisinden sinıflama için çoğunluk oylaması regresyon için ise ortalamaya göre sonuç belirlenir [20].

Adaboost, Freund ve Schapire tarafindan 1996 yılında önerilmiş bir artırım (boosting) algoritmasıdır. Zayıf öğrenicileri bir arada kullanarak güçlü bir öğrenici elde etmeyi amaçlar. Bu yöntemde başlangıçta her bir gözleme aynı ağırlı değeri atanır ve modelin eğitimine başlanır. Her bir iterasyon sonrasında ilgili gözleme ait sonuç doğru ise atanan ağırlık azaltılır yanlış ise ağırlık arttırılır. Belirlenen ağaç sayısına ulaşıncaya kadar modelin eğitimi bu şekilde devam eder [21].

LightGBM (LGB), gradyan artırım algoritmasının farklı bir uygulamasıdır. 2017 yılından beri Microsoft tarafından açık kaynak olarak geliștirilmektedir. Benzer kütüphanelere göre çok daha hızlı çalışmaktadır. Sürekli değişkenlerin histogramlarını çizip kesikli hale getirerek model performansını arttırır ve eğitim süresini kısaltır [22].

XGBoost (XGB), Chen ve Guestrin tarafından 2014 yılında geliştirilmiş ve devamında dağıtık makine 
öğrenmesi topluluğu altında açık kaynak olarak geliștirilmeye devam edilen bir diğer gradyan artırım algoritmasıdır [23].

\section{Bulgular}

Çalıșma kapsamında gerçekleștirilen değișken seçimi, model eğitim ve sinama işlemleri için Python programlama dili kullanılmıştır. Uygulamalarda veri düzenleme işlemleri için pandas, istatistiksel öğrenme yöntem ve değerlendirmeleri için ise scikit-learn, xgboost ve lightgbm kütüphanelerinden yararlanılmıştır.

Uygulamanın ilk aşaması olan değişken seçimi için ağaç tabanlı algoritmalar kullanılarak her bir değişkenin önem düzeyleri belirlenmiştir. Buna göre AdaBoost, ExtraTrees ve RF yöntemleri grid arama (grid search) yöntemi ile çeşitli parametreler ile denenerek en iyi sonuç veren modeller elde edilmiştir. Değișken seçimi Şekil 1'de verilen akıştaki aşamalar sonucu gerçekleştirilmiştir.

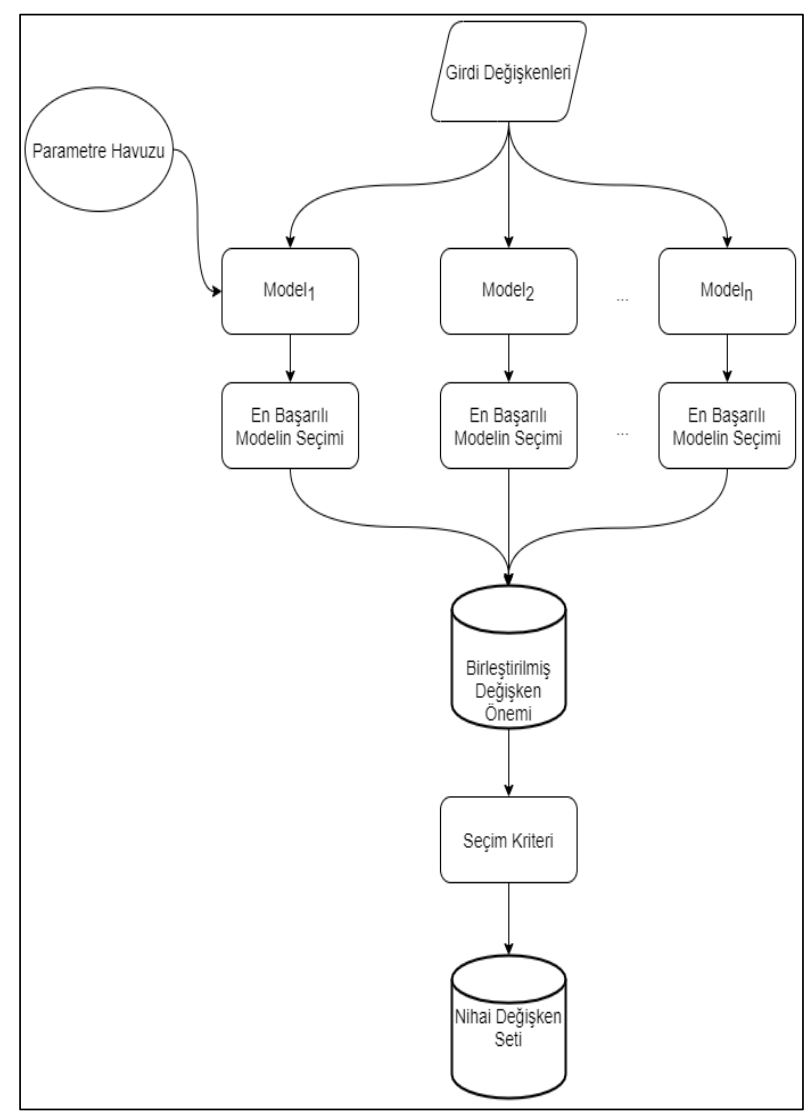

Şekil 1. Değişken seçim süreci.

Değişken seçiminin ilk aşaması ExtraTrees, RF ve AdaBoost algoritmaları için ağaç sayısı, öğrenme katsayısı, en küçük ayrım noktası gibi parametrelerin belirlenmesidir. $\mathrm{Bu}$ amaç doğrultusunda sırasıyla her bir algoritma için farklı parametre kombinasyonları ile on katlı çapraz doğrulama kullanılarak modeller oluşturulmuştur. Elde edilen modeller arasından en yüksek çapraz doğrulama skoru sağlayan parametreler ile en iyi modeller kurulmuştur. Bu modellerin sonucunda her bir değişken için elde dilen değişken önem düzeylerinin sıralanarak değerlendirilmesi değişken seçiminin takip eden aşamasını oluşturmaktadır. ExtraTrees, RF ve AdaBoost algoritmalarından gelen ve önem düzeylerine göre sıralanan üç ayrı değişken seti tekrar eden değişkenler çlkarılarak birleștirilmiştir. Belirlenen eșik değeri olan ortalama değişken düzeyi üzerinde kalan ve tekrar eden değişken isimlerinin çıkarılması ile değişken seçimi tamamlanmıştır. Buna göre çalıșmada kullanılan 193 adet değișkene sahip veri seti uygulanan değișken seçimi sonrasında ağırlıklı olarak kısmi yükler, alt bölümlere ayrılmış yüzey alanı ve bitişiklik ve uzakllık matrisi değişken gruplarından gelen 72 adet değişkenden oluşan nihai veri setine dönüştürülmüştür.

Seçilen değişkenlerin mutajenisiteyi belirlemede ne kadar etkili olduğunun ortaya koyulabilmesi için uygulamalar hem indirgenmemiş 193 adet değişkene sahip veri seti ile hem de 72 adet değișkene sahip indirgenmiş veri seti ile gerçekleștirilmiştir. Tablo 24'te verilen algoritmalar için parametre en iyilemesi yapılarak sonuçlar elde edilmiştir. Tüm değişkenlerin dahil edildiği başlangıç veri setine uygulanan algoritmaların her biri için elde edilen doğruluk, duyarlılık ve özgüllük değerlendirme ölçütleri Tablo 2'de verildiği gibidir. Bu tabloya göre, tüm değişkenlerin kullanılması durumunda \%88.43 doğruluk yüzdesi ile ExtraTrees ve çok yakın başarı yüzdesi ile RF mutajenisite tahmininde en başarılı algoritmalardır. Sonuç olarak tüm değişkenler kullanılarak \%86 ile \%88 arasında bir başarım elde edilmiştir.

Tablo 2. Değişken seçimi yapılmadan önceki model bașarımları (model parametreleri en iyilenmiștir).

\begin{tabular}{cccc}
\hline Model & Doğruluk & Duyarlılık & Özgüllük \\
\hline Bagging & 0.8782 & 0.8608 & 0.8923 \\
ExtraTrees & 0.8843 & 0.8635 & 0.8996 \\
Random Forest & 0.8834 & 0.8635 & 0.8996 \\
LightGBM & 0.8603 & 0.8299 & 0.8850 \\
XGBoost & 0.8812 & 0.8669 & 0.8929 \\
\hline
\end{tabular}

Tüm değişkenlerden oluşan veri setine uygulanan yöntemler değişken seçimi sonrasında elde edilen veri setine parametre en iyilemesi yapilarak tekrar uygulanmıștır. Buna göre Tablo 3'te özetlendiği üzere indirgenmiş veri seri ile elde edilen tüm doğruluk oranlarında tüm değișkenleri içeren veri seti doğruluk oranlarına göre artışlar elde edilmiştir. RF algoritması Tablo 2'deki başarı yüzdesi ile karşılaştırıldığında indirgenmiş veri için \%1,6 artışla yaklaşık \%90 doğruluk başarımına ulaşmıştır. Benzer biçimde Tablo 3 incelendiğinde, mutajenisite tahmininde daha etkili olduğu düşünülen 72 değişken ile elde edilmiş başarı yüzdelerinde tüm değişkenleri kullanarak elde edilen bașarı yüzdelerine göre artıșlar gözlenmiștir. LightGBM algoritmasının doğruluk oranındaki \%3'lük artış da dikkat çekicidir. Her iki veri seti ile elde edilen sonuçları daha net göstermek adına bu farklar Tablo 4'te verilmiștir. 
Tablo 4 incelendiğinde değişken seçimi sonrasında tüm modellerde ortalama \%1.65'lik başarı artışı görülmektedir. Toksisiteye yol açması nedeniyle oldukça önemli olan mutajenisitenin etkili değişkenler ile birlikte belirlenmesinde in-silico yaklaşım ile elde edilen \%1,65'lik artış önemli bir artış olarak değerlendirilebilir.

Tablo 3. Değiş̧ken seçimi sonrası model başarımları (Model parametreleri en iyilenmiștir).

\begin{tabular}{cccc}
\hline Model & Doğruluk & Duyarlılık & Özgüllük \\
\hline Bagging & 0.8904 & 0.8662 & 0.9095 \\
ExtraTrees & 0.8892 & 0.8703 & 0.9045 \\
Random Forest & 0.8993 & 0.8779 & 0.9168 \\
LightGBM & 0.8935 & 0.8862 & 0.9157 \\
XGBoost & 0.8975 & 0.8820 & 0.9101 \\
\hline
\end{tabular}

Tablo 4. Değişken seçimi yapılan veri ve tüm veriye uygulanan modellerin başarım farkları.

\begin{tabular}{cccc}
\hline Model & $\begin{array}{c}\text { Doğruluk } \\
\text { (Değișken } \\
\text { seçimi) }\end{array}$ & $\begin{array}{c}\text { Doğruluk } \\
\text { (Tüm } \\
\text { Veri) }\end{array}$ & $\begin{array}{c}\text { Doğruluk } \\
\text { (Fark) }\end{array}$ \\
\hline Bagging & 0.8904 & 0.8782 & 0.0122 \\
ExtraTrees & 0.8892 & 0.8843 & 0.0049 \\
Random Forest & 0.8993 & 0.8834 & 0.0159 \\
LightGBM & 0.8935 & 0.8603 & 0.0332 \\
XGBoost & 0.8975 & 0.8812 & 0.0163 \\
\hline
\end{tabular}

\section{Tartışma ve Sonuç}

$\mathrm{Bu}$ çalışmanın amacı, in-silico yaklaşım kapsamında öğrenme algoritmalarının toksisite testleri arasında ortaya çlkabilecek genetik değişimi yani mutajenisiteyi belirleme sürecinde ne derece etkili olabileceğini ortaya koymaktır. $\mathrm{Bu}$ amaç doğrultusunda kullanılan veri seti, mutajenisite aktif olan ve olmayan 10835 molekül için 193 adet değişken, MOE programı ile hesaplatılarak elde edilmiştir. Çalışma değişken seçimi ve mutajenisite tahmini olmak üzere iki genel aşamada gerçekleştirilmiştir. Değişken seçimi aşamasında, veri seti üzerinde ağaç tabanlı algoritmalar olan AdaBoost, ExtraTrees ve RF istatistiksel öğrenme algoritmaları uygulanarak 10 katlı çapraz doğrulama kullanılarak grid arama yaklaşımı ile en iyi parametre seçimi gerçekleştirilmiştir. Elde edilen en iyi parametreler ile kurulan modeller sonucunda ağaç tabanlı modellerden elde edilen değişkenlere ait gini indeksi değerleri kullanılarak mutajenisiteyi tahminlemedeki önem düzeyleri belirlenmiştir. Bu bilgiler ile veri setinin boyutu mutajenisiteyi tahminlemede en etkili 72 değișkene indirgenmiştir. Çalıșmada seçilen değişkenler incelendiğinde 72 etkili değișkenin çoğunluğunun (yaklaşık \%70) kısmi yükler, alt bölümlere ayrılmış yüzey alanı ve bitişiklik ve uzakllık matrisi değişkenlerini içeren gruplardan geldiği gözlenmektedir. Fiziksel özellikler içeren gruptan reaktif grupların varlığını gösteren özellik ile potansiyel olarak toksik grupların varlığını gösteren özellik mutajenisite tahmininde model tarafindan belirlenen en etkili özelliklerin başında gelmektedir. Mutajenisite tahmin aşamasında, seçilen bu tanımlayıcı değişkenlerden oluşan yeni veri setine doğrusal ve doğrusal olmayan 19 farklı istatistiksel öğrenme algoritması uygulanmış, aralarından en iyi sonuç veren beş topluluk öğrenme algoritması seçilmiştir. Seçilen algoritmalar olan Bagging Extra Trees, LightGBM, RF ve XGBoost için yeni değişkenlerden oluşan veri seti kullanılarak tekrar parametre en iyilemesi yapılmıştır. Değişken seçimiyle birlikte yaklaşık \%63 oranında boyut indirgemesi yapılmış veri setlerine uygulanmış, değişkenlerin tamamı ile elde edilen sonuçlara göre model başarımlarında \%1-3 arası artışlar gözlenmiştir. Sonuç olarak değişken seçimi ve parametre en iyilemesi ile modellerin çoğunda \%90'a varan başarım elde edilmiştir.

$\mathrm{Bu}$ sonuçlar göstermiştir ki, toksisiteye yol açması nedeniyle özellikle erken evrelerde belirlenmesi çok önemli olan mutajenisite için laboratuvar ortamında (in vitro) ve canlı üzerinde (in vivo) yapılan uzun ve maliyetli çalışmalar öncesinde in-silico yaklaşımlar ile oldukça önemli bulgular elde edilebilmektedir. Günümüz teknolojisi göz önünde bulundurulduğunda bu tür alanlarda in-silico yaklaşımların tercih edilmesi zaman, maliyet ve iş gücündeki azalma nedeni ile çok daha yaygınlaşacaktır.

Çalışmada, değişken seçimi için ağaç tabanlı yöntemler tercih edilmiştir. İleride yapılacak çalışmalarda, değişken seçimi filtre ve sarmal (wrapper) yöntemlere ek olarak L1 (Manhattan) ve L2 (Öklid) düzenlileştirmesi kullanan yöntemler olan Lasso ve Ridge regresyon ile de yapılabilir. Çalışmanın birçok aşamasında kullanılan parametre seçiminde tercih edilen grid arama yönteminde seçilen parametre uzayındaki kombinasyonlar ile arama yapıldı̆̆ı için bazı sınırlamalar bulunmaktadır. Örneğin doğru öğrenme katsayısı seçilmiş olmasına rağmen ağaç sayısı yeterli olarak verilmez ise model, belirlenen parametre uzayında bulunan en iyiyi bulacak, daha iyi sonuç veren bir kombinasyonu deneyemeyecektir. $\mathrm{Bu}$ duruma alternatif olarak ise Bayesçi parametre en iyilemesi ile daha iyi sonuç veren parametreler elde edilebilmesi mümkün olmakla birlikte Bayesçi parametre en iyilemesinde de en iyileme ișleminin zaman maliyetinin yüksek olduğu unutulmamalıdır.

\section{Teşekkür}

Bu çalışma, Mimar Sinan Güzel Sanatlar Üniversitesi Bilimsel Araştırma Projeleri Komisyonu tarafından desteklenmiştir. (Proje No: 2018-30).

\section{Etik Beyanı}

Bu çalışmada, "Yükseköğretim Kurumları Bilimsel Araştırma ve Yayın Etiği Yönergesi" kapsamında uyulması gerekli tüm kurallara uyulduğunu, bahsi geçen yönergenin "Bilimsel Araştırma ve Yayın Etiğine Aykırı Eylemler" başlığı altında belirtilen eylemlerden hiçbirinin gerçekleştirilmediğini taahhüt ederiz. 


\section{Kaynakça}

[1] Honma, M., Kitazawa, A., Cayley, A., Williams, R. V., Barber, C., Hanser, T., Saiakhov, R., Chakravarti, S., Myatt, G. J., Cross, K. P., Benfenati, E., Raitano, G., Mekenyan, O., Petkov, P., Bossa, C., Benigni, R., Battistelli, C. L., Giuliani, A., Tcheremenskaia, O., ... Rathman, J. 2019. Improvement of quantitative structure-activity relationship (QSAR) tools for predicting Ames mutagenicity: Outcomes of the Ames/QSAR International Challenge Project. Mutagenesis, 34(1) 41-48.

[2] Bakhtyari, N. G., Raitano, G., Benfenati, E., Martin, T., Young, D. 2013. Comparison of in silico models for prediction of mutagenicity. Journal of Environmental Science and Health - Part C Env. Carcinogenesis and Ecotoxicology Reviews, 31(1), 45-66.

[3] Hansch, C. 1980. Use of quantitative structureactivity relationships (QSAR) in drug design (review). In Pharmaceutical Chemistry Journal 14(10).

[4] Greene, N., Judson, P. N., Langowski, J. J., Marchant, C. A. 1999. Knowledge-based expert systems for toxicity and metabolism prediction: DEREK, StAR and METEOR. SAR and QSAR in Environmental Research, 10:2-3, 299-314.

[5] Hanser, T., Barber, C., Rosser, E., Vessey, J. D., Webb, S. J., Werner, S. 2014. Self organising hypothesis networks: A new approach for representing and structuring SAR knowledge. Journal of Cheminformatics, 6(21).

[6] Mazzatorta, P., Tran, L. A., Schilter, B., Grigorov, M. 2007. Integration of structure - Activity relationship and artificial intelligence systems to improve in silico prediction of ames test mutagenicity. Journal of Chemical Information and Modeling, 47(1), 34-38.

[7] Zheng, M., Liu, Z., Xue, C., Zhu, W., Chen, K., Luo, X., Jiang, H. 2006. Mutagenic probability estimation of chemical compounds by a novel molecular electrophilicity vector and support vector machine. Bioinformatics, 22(17), 2099-2106.

[8] Liao, Q., Yao, J., \& Yuan, S. 2007. Prediction of mutagenic toxicity by combination of Recursive Partitioning and Support Vector Machines. Molecular Diversity, 11, 59-72.

[9] Xu, C., Cheng, F., Chen, L., Du, Z., Li, W., Liu, G., Lee, P. W., Tang, Y. 2012. In silico prediction of chemical ames mutagenicity. Journal of Chemical Information and Modeling, 52(11), 2840-2847.

[10] Moorthy, N. H. N., Kumar, S., Poongavanam, V. 2017. Classification of carcinogenic and mutagenic properties using machine learning method. Computational Toxicology, 3, 33-43.
[11] Zhang, H., Kang, Y. L., Zhu, Y. Y., Zhao, K. X., Liang, J. Y., Ding, L., ... Zhang, J. 2017. Novel naïve Bayes classification models for predicting the chemical Ames mutagenicity. Toxicology in Vitro, 41, 5663.

[12] Webb, S. J., Hanser, T., Howlin, B., Krause, P., Vessey, J. D. 2014. Feature combination networks for the interpretation of statistical machine learning models: application to Ames mutagenicity. Journal of cheminformatics, 6(1), $1-21$.

[13] Seal, A., Passi, A., Jaleel, U. A., Wild, D. J., Open Source Drug Discovery Consortium. 2012. Insilico predictive mutagenicity model generation using supervised learning approaches. Journal of cheminformatics, 4(1), 10.

[14] Ji, X., Tong, W., Liu, Z., Shi, T. 2019. Five-feature Model for Developing the Classifier for Synergistic vs Antagonistic Drug Combinations Built by XGBoost. Frontiers in Genetics, 10, 1-13.

[15] Hansen, K., Mika, S., Schroeter, T., Sutter, A., Ter Laak, A., Steger-Hartmann, T., ... Müller, K. R. 2009. Benchmark data set for in silico prediction of Ames mutagenicity. Journal of chemical information and modeling, 49(9), 2077-2081.

[16] Kazius, J., McGuire, R., Bursi, R. 2005. Derivation and validation of toxicophores for mutagenicity prediction. Journal of medicinal chemistry, 48(1), 312-320.

[17] MOE, Molecular Operational Environment. Chemical Computing Group Inc., Montreal, Canada.

[18] Breiman, L., 2021. Random forests. Maching Learning, 45(1), 5-32.

[19] Geurts, P., Ernst, D., Wehenkel, L. 2006. Extremely randomized trees. Machine learning, 63(1), 3-42.

[20] Breiman, L. 1996. Bagging predictors. Machine learning, 24(2), 123-140.

[21] Freund, Y., Schapire, R. E. 1996. Experiments with a new boosting algorithm. Machine Learning: Proceedings of the Thirteenth International Conference, July 1996, Italy 148-156.

[22] Ke, G., Meng, Q., Finley, T., Wang, T., Chen, W., Ma, W., ... Liu, T. Y. 2017. Lightgbm: A highly efficient gradient boosting decision tree. In Advances in Neural Information Processing Systems, Dec 4-9, Long Beach, CA 3146-3154.

[23] Chen, T., Guestrin, C. 2016. Xgboost: A scalable tree boosting system. In Proceedings of the 22nd ACM SIGKDD International Conference on Knowledge Discovery and Data Mining, August 2016, San Fransisco, California, 785-794. 